\title{
An Analytical Reverse Engineering of IELTS Listening Tasks for a Construct Model
}

\author{
Masood Khalili Sabet ${ }^{1}$, Hamid Reza Babaee Bormanaki²* \\ ${ }^{1}$ Department of English, Faculty of Human Science and Literature, University of Guilan, I, R. Iran \\ ${ }^{2}$ Department of Teaching English as a Foreign Language, Faculty of Human Science and Literature, University of Guilan, I, R. Iran \\ Corresponding Author: Hamid Reza Babaee Bormanaki, E-mail: hreza86b@gmail.com
}

\begin{abstract}
ARTICLE INFO
Article history

Received: May 08, 2017

Accepted: July 20, 2017

Published: December 01, 2017

Volume: 6 Issue: 7

Special Issue on Language \& Literature

Advance access: September 2017

Conflicts of interest: None

Funding: None

ABSTRACT

The study reported here was concerned with the issue of reverse engineering of language test items as it relates to the identification of the language constructs underlying listening tasks of LELTS test. In this regard, the IELTS examination papers, from IELTS 1 to IELTS 10 were compiled as a corpus for the analysis. Tasks were analyzed using a taxonomic frame work adopted from Moore, Morton and price (2012), that was originally adapted from Weir and Urquhart (1998), with a focus on two dimensions of difference: level of engagement, referring to the level of text with which a listener required to engage in order to respond to a task (local vs. global); type of engagement referring to the way (or ways) listeners expected to engage with a text in order to process the material to respond to a task (literal vs. interpretative). Overall, the analysis found evidences of bottom up processing underlying most IELTS listening tasks. The majority of tasks were identified to have a 'local-literal' configuration on their orientation, demanding primarily a basic understanding of relatively small textual units of the material. The results of the study were used to suggest the practical implications for the four groups of the people involved in the IELTS educational contexts: participants; teachers; material preparation experts, and curriculum designers.
\end{abstract}

Key words: IELTS Listening Test, Reverse Engineering, Taxonomic Framework, Level of Engagement, Type of Engagement, Bottom Up Processing

\section{INTRODUCTION}

IELTS is an International English Language Testing System which is developed to measure the language ability of participants who want to educate or work in countries where English is the language of communication (IELTS 10, 2015). It corresponds to the highest international principles of language assessment and is also acknowledged by professional bodies, immigration authorities and other government agencies, universities and employers in many countries, including Australia, Canada, New Zealand, the UK, the USA (IELTS handbook, 2007). In recent years, the number of IELTS participants has been increased due to some reasons. The reasons has been the results of an increase in the number of students wanting to study in English-speaking countries along with the increase in the case of the universities and institutions setting an IELTS score as a prerequisite for their requirements (Moore \& Morton, 2007).

According to the (IELTS 10, 2015), IELTS consists of two module, academic and general training. Both modules cover all four language skills - listening, reading, writing and speaking. Everyone takes the same listening and speaking tests but there are different reading and writing tests for the two modules. As far as skills are concerned, listening section of IELTS tests is one of the sections that have had a significant role on the participants' success. Although participants' preparedness to meet the listening tasks is their important responsibility having a significant role on their success, being familiar with the constructs underlying the IELTS listening tasks is the other factor that can be conceived of having considerable importance on their' success. Moreover, from many of students participated in the IELTS test, to some extent, some of them couldn't achieve an appropriate band score. In this sense, one of the skills that has had a considerable effect on their performance and causes some problems for them lowering their whole score on the test has been thought to be listening. The reason for this difficulty lies on the abilities or constructs underlying listening module through which test takers can successfully respond to the tasks.

Constructs are abilities required to respond to a task. As Fulcher (2010) put it, constructs are "the abilities of the learner that we believe underlie their test performance, but which we cannot directly observe (p.96). Carroll (1987) introduced the 'mental abilities' as constructs and defined them in terms of mental tasks which students are thought to have in order to meet the demands of a test. The overarching appreciation of constructs as abilities points to the paramount importance of the construct identification process as a research toll for 
making the IELTS participants aware of the constructs, skills or behaviors underlying IELTS listening tasks types as a requirement necessary for them to be successful in giving appropriate answers to the test. Therefore, the issue of increasing number of IELTS participants and its' overriding influence on their academic life and the significant importance of the constructs in answering a language test suggests the need for, the revelation of the listening constructs underlying the test. In this study, the researcher has implemented an analytical framework to reveal the constructs of listening underlying the IELTS listening module through the analytical reverse engineering process.

\section{LITERATURE REVIEW}

\section{Background to the IELTS Listening Test}

According to the IELTS handbook (2007) the IELTS system in its current form provides one type of listening test both in general training module and in academic module. An IELTS listening test is typically comprised of four sections. The first two sections are concerned with social needs including a dialogue among two interlocutors and the second section is a monologue articulated by one speaker. The final two sections are dealt with situations concerned closely with didactic or instructional contexts. The third section is dealt with a dialogue among more than four people and the fourth section again includes a monologue. Along with the listening sections is a range of tasks (40 in total) used to test students comprehension of material in the 30 minutes allocated. These tasks are characterized by IELTS 10 (2015) as: 1 . Multiple choice items, 2. Short answer items, 3. Completion items (e.g., Note/summary/flow-chart/table/sentence/form completion), 4. Labeling a diagram/plan/map, 5. Classification items, and 6. Matching items.

\section{Previous Studies of IELTS Listening Test}

As mentioned, the focus of the current study is exclusively on the identification of the language constructs underlying IELTS listening tasks. Cronbach and Meehl (1955) defined constructs as 'a postulated attribute of people, assumed to be reflected in test performance' (p. 283). As was stated earlier, Fulcher (2010) defined constructs as "the abilities of the learner that we believe underlie their test performance, but which we cannot directly observe (p.96). In a similar vein, Carroll (1987) called the constructs as mental abilities and defined them in terms of mental tasks which students are thought to have in order to meet the demands of a test. From different perspective, Kerlinger and Lee (2000) described constructs as concepts that are modified for scientific enquiry. Fulcher and Davidson (2009) related the language constructs to the design patterns in architecture and put a great emphasis on the constructs as a basic requirement. Overall, since its acknowledgement as abilities and processes affecting test interpretation and use, a number of studies have been reported in the construct realm, especially in the domain of construct validation enquiry in language testing. As far as listening comprehension is concerned, construct validity is the extent to which our test measures the model of listening underlying the test and in this sense construct validity concerned with the abilities that the test takers supposed to have in order to meet the requirements of the target language domain (Moore, Morton, \& Price, 2012). In the case of IELTS listening test, the domain is both academic-oriented listening and listening to spoken language in social contexts (e.g., listening to every day conversations, listening to media, etc.). Therefore, scanning for specific information which is an important requirement in university contexts (e.g., Listening to the lectures) should be taken into consideration as a listening construct and hence, tests constructed in related contexts should be equipped to diagnose the ability to swiftly find explicit information (Alderson, 2000).

The studies conducted on the domain of IELTS listening validation, have tried to investigate the degree of the validity of the IELTS listening test. Whilst some of these studies have been designed specifically for the purpose of test validation (e.g., Badger \& Yan, 2012; Breeze \& Miller, 2012; Field, 2012), others which were conducted in integration with the other skills (e.g., speaking) (Nakatsuhara, 2012), have been motivated by more communicational and productive interests, especially to assist in the processes of speaking and production of a language. One of the studies that focused on the construct validity of IELTS listening module was that of John Field's (2012) study on the cognitive validity of the lecture-based question in the IELTS Listening paper. Utilizing the theoretical framework of test validation drawn from Weir (2005), he found some differences between the processes underlying lecture-based listening and those of IELTS listening and raised questions about the cognitive validity of the IELTS listening section that was the evidence of the construct invalidity of the test. In another similar research conducted on the domain of the construct validity of the IELTS listening section, Badger and Yan (2012) employed the similar method in order to compare the utilization of tactics and strategies in the IELTS Listening test by native speakers of English and learners of English with Chinese as their native language. In contrast to the study carried out by Field (2012), Badger and Yan's findings demonstrated the construct validity of the IELTS section by providing evidence in similarity between the cognitive processes underlying native speakers' task performances and those of non-native speaker's performances. Breeze and Miller (2012) undertook a study to evaluate the predictive validity of IELTS listening section test as an entry test on three bilingual degree programs in a large Spanish university for which they proposed appropriate cutoff scores. Results of this study proved the traditional belief that a general band score of 6.5 is the rational cutoff score for the university permission. One study, which was not conducted as a construct validation research, but which led itself to such interpretation, was Nakatsuhara (2012). In this study in which, in addition to listening, speaking has also been taken into consideration, Nakatsuhara examined the relationship between test takers' listening proficiency and their performance on the IELTS Speaking test. His study proved the construct validity of IELTS speaking test in a way that by an administration of comprehensive evaluation of test takers' 
speaking ability, their oral communication skills can be elicited and evaluated.

Overall, the studies reviewed above in the domain of IELTS listening module, have examined this skill from different perspectives. Some of them investigated the construct validity of the test, examining the processes underlying the test takers' performances under the test conditions. One of the studies inspected the predictive validity of the IELTS listening and the other, examined the IELTS listening in comparison with the speaking module. In recent years, however, there has not been reported any study on the domain of identifying the language constructs underlying the IELTS listening module employing task analysis by analyzing the listening tasks through reverse engineering process. Therefore the current study aims to investigate the IELTS listening module from this point of view and analyze the listening tasks using a taxonomic framework for the purpose of the revelation of language constructs underlying the tasks.

\section{Reverse Engineering}

Reverse engineering is not a newly-developed domain of science in other fields, especially in hard sciences. This has been a common practice in physical and other engineering sciences for decades. The history of it goes back to ancient origin, however, about a decade ago, this method has been coined and extended to language testing science by Davidson and Lynch in 2002 (Fulcher \& Davidson, 2007). In the field of testing, as Fulcher (2010) put it, it refers to "looking at a test item or tasks and trying to work out what construct(s) it is trying to test" (p. 123). It is also advantageous in a process of test selection for a group of learners based on their needs through the investigation of the degree of match or mismatch between test and learners' needs (Fulcher, 2010). In other cases, language testing researchers try to investigate the item-spec congruence to see the degree of correspondence between the item specification and the designed tests. This kind of reverse engineering is conducted especially in the evaluation phase of the test design cycle.

Fulcher and Davidson (2007) provided five types of reverse engineering as follows:

1. Straight reverse engineering: This type of reverse engineering refers to the act of inferring guiding language about existing items without altering the existing items at all.

2. Historical reverse engineering: This is conducted when the purpose is doing reverse engineering across several existing versions of a test. In other words, a straight reverse engineering refers is conducted across the numerous versions of a test.

3. Critical reverse engineering: This the most common form of reverse engineering, and refers to the critically analyzing an item to know whether the test does measure what is supposed to measure.

4. Test deconstruction reverse engineering: Whether critical or straight, whether historical or not, this type of reverse engineering presents information beyond the test context uncovering some larger realities.
5. Parallel reverse engineering: In this type, teachers are expected to construct tests based on the external standards suited outside the classroom and simultaneously, they may not consult fully with one another.

Although different types of reverse engineering overlap with one another in some parts (Fulcher \& Davidson, 2007) and provide straightforward pathways for construct-identification processes, the current study made use of a newly-developed type proposed by the authors in this research - analytical reverse engineering - that is, going from items to constructs with analytically engaging practices in different perspectives. The idea for proposing this type of reverse engineering comes from the multidimensionality of requirements of different tasks. In this research, due to this multidimensionality, it seemed rational for the tasks to be analyzed from different angles for the purpose of the comprehensive revelation of the constructs underlying the IELTS listening tasks. Thus, following this type of RE, it is tried to reveal the language construct underlying IELTS listening task-types through the analytical framework of task analysis.

\section{METHOD}

\section{Design}

The study had a qualitative design. An analytical framework employed as a qualitative analysis instrument for analyzing the IELTS task-types. Beside the rudimentary arithmetic procedures used for the calculation of the tasks frequencies in the corpus, no quantitative and experimental methods and statistics used for the analysis of each task-type. The analytical framework used for the analysis is in line with the requirements of the analytical reverse engineering. This framework, as will be stated in the following parts, searches for the constructs underlying tasks from different angles and perspectives. In this sense, applying this framework, unlike straight reverse engineering analytical RE is subject to analysis in multiple levels of language from deep levels to surface levels.

\section{Instruments}

The instruments used to reveal the constructs underlying the listening tasks of IELTS test were IELTS examination papers and the taxonomic framework. In order to get a comprehensive picture of the constructs underlying listening tasks, a corpus of IELTS listening test samples were compiled for the study. These were from the practice test materials published by Cambridge University Press (see Appendix 1 for list of corpus materials). Generally, In the IELTS task survey, a total of 40 complete tests from IELTS 1 to IELTS 10 was investigated, each made up of a variety of task types. To analyze the IELTS listening task-types in order to get a rational picture about the constructs of interest, the taxonomic and analytical framework was selected and employed. This framework was exactly the same framework used in validation study of the IELTS reading test conducted by several members of the research team (Moore\& Morton and Price, 2012). Although the framework was used by (Moore \& Mor- 
ton and Price, 2012), it was originally adopted by them in a large part from the componential schema of Weir and Urquhart (1998) that was utilized in another latest enquiries of the IELTS Academic Reading test accomplished by Weir et al. (2009). According to Moore\& Morton and Price (2012) the framework had two dimensions of difference as follows:

\section{Dimension 1: Level of engagement}

The first dimension of analytical framework is what (Moore \& Morton and Price, 2012, p.9) called 'level of engagement with text". Concerning this study, this dimension refers to the quantity of a text that the listener is needed to engage with, in order to respond to a task. This quantity might be local or global. Local quantity refers to tasks that require quite circumscribed sections of a text (e.g. single sentences, or groups of sentences), on the other hand, global quantity refers to the tasks that appraise larger textual units (e.g. a series of paragraphs, or a whole text). However, there are some tasks that involve the integration of both global and local quantity of the text.

\section{Dimension 2: Type of engagement}

The second dimension of analytical framework is what (Moore \& Morton and Price, 2012, p.9) termed 'type of engagement with text", adapted from Weir and Urquhart (1998) componential schema. In this regard, according to Moore, Morton \& Price (2012) the focus is more on what is needed to be done with texts, that is to say the prescribed outcomes of the Listening. In developing this dimension, they drew initially on the distinction traditionally made in linguistics between semantic and pragmatic meaning. This basic distinction between semantic and pragmatic meaning of a text paved the way for them to develop the second category of their framework in accordance with Weir and Urquhart's (1998) componential schema. According to this category, type of engagement refers to the way (or ways) a listener is expected to engage with text in order to process the material to respond to the task. This ways or processes can be literal or interpretive. Literal engagement being in line with bottom-up processing denotes to the literal comprehension of the material, whereas, interpretive engagement being in consistent with the top-down processing points to the pragmatic understanding of the textual units. The two dimensions of the analytical framework - level of engagement and type of engagement - are demonstrated on the matrix shown in Figure 1 below from Moore\& Morton and Price (2012, p.12).

\section{Procedure}

The study was conducted in three steps: first of all the representative samples of IELTS listening tasks taken from IELTS examination papers and practice test materials published by Cambridge University Press compiled as a comprehensive corpus for the study (see Appendix 1). Next, a preliminary analysis was conducted on the tasks-types drawn from the sample materials based on the number of occurrences of each task-type in the corpus and their number of occurrences

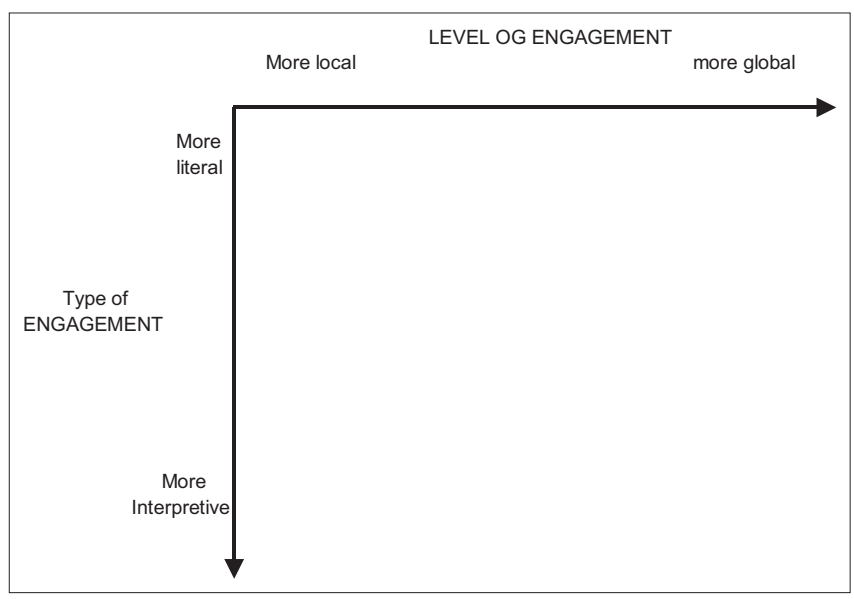

Figure 1. Analytical framework used in the study (Moore \& Morton and Price, 2012)

along with the total number of items under each task-type and average number of items per use of each task were presented in a table. Finally, to conduct the main part of the research and compile data for the construct identification component of the study, each task-type was analyzed by the researcher based on the two dimensions of the study's analytical framework (i.e. the 'level' and 'type' of engagement).

\section{ANALYSIS AND FINDINGS}

\section{IELTS Listening Tasks}

The IELTS corpus compiled for the study consisted of a total of 40 listening tests of IELTS 1 to IELTS 10, with each of these tests made up of four listening sections. In all, the total number of listening tasks across the corpus was 348, comprising 1575 individual items. A preliminary analysis found a variety of task types, with some featuring regularly in the corpus, and others less so. Table 1 lists the different task types identified, along with their relative frequencies. The figures in the left hand column show the total number of uses of each task type in the corpus, and those in the center column, the total number of items under each of these types. Thus in the table, we can see for example, that the completion item format was used 175 times in the corpus, which included a total of 824 individual items (an average rate of 4.7 items per use of task type - see right hand column). Note that the order of frequency of task types in the table is based on the 'no of occurrences of task type in corpus' - see the left hand column.

It is noted that, In order to get a comprehensive picture of the constructs underlying these task types, each of completion task-types are assigned under the general heading of completion tasks. Thus, in what follows, a description is provided for five main task-types identified namely; completion tasks, multiple choice tasks, multiple option tasks, information-category match tasks, Labeling tasks and short answer tasks, along with the discussion of how each relates to the 'level of engagement - type of engagement' dimensions used for the analysis. It is noted that in the corpus assembled for the study, the first of task types -completion items- accounted overall for more than half of the total items (50.2\%). 
Table 1. Task types by frequency

\begin{tabular}{lccc}
\hline Task type & $\begin{array}{c}\text { No of occurrences of task } \\
\text { type in corpus (\% in bracket) }\end{array}$ & $\begin{array}{c}\text { Total number of items under } \\
\text { task type (\% in brackets) }\end{array}$ & $\begin{array}{c}\text { Average no of items } \\
\text { per use of task }\end{array}$ \\
\hline Completion items & $175(50.2)$ & $824(52.3)$ & 4.7 \\
Multiple choice items & $83(23.8)$ & $321(20.3)$ & 3.8 \\
Multiple option items & $36(10.3)$ & $87(5.5)$ & 2.4 \\
Information-category match items & $25(7.1)$ & $112(7.1)$ & 4.4 \\
Labeling items & $17(4.8)$ & $66(4.1)$ & 3.8 \\
Short answer items & $12(3.4)$ & $39(2.4)$ & 3.2 \\
Total & $348(100 \%)$ & $1575(100 \%)$ & 4.1 \\
\hline
\end{tabular}

\section{Type 1: Completion items}

Completion tasks were the first most common format, accounting for $50.2 \%$ of all task types in the corpus (Table 1 ). Six types of this format was found in the corpus in terms of the prompt with which test takers were expected to engage in order to respond to the task: note completion $(21.5 \%)$, table completion $(14.3 \%)$, form completion $(6.3 \%)$, sentence completion $(6.3 \%)$, summary completion $(1.6 \%)$, and flowchart completion $(0.2 \%)$. In each of these types, test takers needed to follow the listening material, locate the words and the phrases of the prompt in the text and find the required information by the prompt in the listening text. Sample 1 presented in appendix 1 is an example of the completion task formats - Note completion task - showing several sample items being representative of other completion tasks.

\section{Level of engagement}

With respect to text 'level', it is noted that in the design of these tasks, first test takers are expected to locate the single sentence proposition, phrase or word contained in the prompt within the semantic unit of similar or slightly different length in the listening text, and then find the required information by the prompt. As seen in the second item of the sample (presented in Appendix 1), the test taker needs to be engaged with the local level of the listening text in order to locate the following prompt:

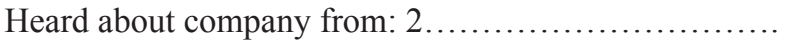

Then find the relevant information in the semantic unit of similar length in the conversation:

I heard about you in the newspaper.

This was not always the case however. In the last item of the sample, for example, it is noted that whereas the prompt is a single sentence:

Poisons from 5 . ..are commonly consumed by whales.

The relevant information in the lecture stretched over a larger grammatical unit than the prompt. In the following excerpt from lecture, it can be seen that the relevant information required by the prompt statement occur inter-sententially in the two sentences (shown in bold).

Another theory is related to toxins or poisons, these have also been found to contribute to the death of marine animals. Many toxins, as I'm sure you are aware, are originate from plants, or animals.
Some variation was noted in the length of these sections, ranging from a single word to four sentences in the listening material. This variation in engagement level is captured on the 'local - global' scale in Figure 2. Overall, it was found that most tasks of this type, hence, completion task-types require engagement at or around word, phrase and sentence level. Accordingly in the analysis, such tasks were assigned to the local end of the local-global continuum.

\section{Type of engagement}

The type of engagement required for the completion tasks is one of establishing the semantic connection between two distinct units of information (one in the propositional content of the prompt, and a cognate one that needs to be located by the test-taker in the text), and to find the information required by the prompt in the listening material or text. For example, considering the item 3 of the sample:

Los Angles: customer wants to visit some $3 \ldots \ldots \ldots \ldots \ldots \ldots$............ parks with her friends.

The needed information to complete the note is the same as one contained in the prompt (shown in bold):

Travel agent: The first one begins in Los Angeles and there's plenty of time to visit some of the theme parks there.

\section{Correct answer: Theme}

This was not always the case however. In the item 4 of the sample, for example, it is noted that the propositional content of the following prompt:

Some parasites can effect marine animals' $4 \ldots \ldots \ldots \ldots \ldots . . . .$. which they depend on navigation is a paraphrase of the necessary information contained in the text being used to find the answer:

Since marine animals rely heavily on their hearing to navigate, this type of infestation, has the potential to be very harmful.

\section{Correct response: Hearing}

The specific features of completion task types - the need to establish the presence of certain propositional content of the prompt in a listening material, and then to find the information required by the prompt - suggest a strongly 'literal' engagement with listening material. Accordingly, this task type was assigned to the higher end of the 'literal-interpretative' continuum. The preceding analysis gives the configuration shown in Figure 2 ( $T 1 a$ refers to completion tasks). 


\section{Type 2: Multiple Choice Items}

This type was the next most common task-type, accounting for $23.8 \%$ of all types in the corpus (Table 1). For all items of this task type, test-takers were required to select a single 'correct' option from the existing three options. At first, test takers were allowed to read the question in a limited amount of time, then listen to the listening excerpt (monologue and dialogue) and select the correct answer. While listening, they must follow the questions one by one to find the required information from the smaller or larger textual units of the excerpt. Examples of this type are shown in sample 2 below in Appendix 1.

\section{Level of engagement}

The Multiple choice task format in the IELTS corpus was realized and revealed to be different for inferring no specific level of engagement with listening text. This was in contrast with the other task-types considered in the corpus. Thus, it was found for example that the completion formats was linked to engagement at a mainly sentential level; similarly the principal unit of analysis in Information-category match item type was seen to be the smaller units of text. Instead, no such generalization would be inferred from multiple choice items as is evident in the sample items above. In the item 1 and 3 in sample 2 (shown in Appendix 1), for example, the required engagement is at a more 'local', propositional level. As an example, the first item of sample requires the test taker to find the specific type of the information (in this case, Andrew's number of work years in a hospital) in the conversation at the sentence level and select the correct option that is option $\mathrm{B}$, three years.

1. Andrew has worked at the hospital for (IELTS 5 - test 1), (local - literal).
A. Two years
B. Three years
C. Five years

ANDREW: Yes I've been working in the administration section of the local hospital for last three years.

Similarly in another example, the item 3 of sample 2, that is a conversation between a theater student named, Bob and the other student named, Mia, the required level of engagement is local. Therefore, to answer this item:

3. To support the production, research material was used which described (IELTS 10, test 3)
A. Political developments.
B. Changing social attitudes.
E. Economic transformations.

Test taker needs to look for and find the correct answer in the following two sentences of the conversation. In other words, the engagement is at the level of the two sentences.

ROB: well. She found these articles from the 1950s about relationships between children and their parents, or between the public and people like bank managers or the police were shifting.

In contrast, items 2 and 4 of the sample require engagement with a more extended section of the text - what in the passage is a full paragraph, as seen below in the item 2 , or what in the text is all of the full paragraphs as in item 4 . Thus, to answer the item 2 , test takers need to evaluate the correctness of the options of the question taking account of the whole paragraph.

2. The speaker warns the students that

A. Internet material can be unreliable.

B. Downloaded information must be acknowledged.

C. Computer access may be limited at times.

\section{Relevant Material from Listening Extract}

LIBRARIAN: OK, now let me give you an outline of what is available to you. You'll find that the computers are increasingly used as a research tool. Many student must of their research on the internet and the library computers are permanently online. Having found what you need, you'll find you can readily save texts on your personal computer space to print of when you need. You might think that it's the fastest way to get information but the links can be slow. Clearly you can find lots on there nut much of it is useless information as it is from highly debatable sources - so be critical.

Finally, in this regard, item 4 requires consideration of the whole listening material - a listening text including 7 paragraphs $($ Correct response $=\mathrm{B})$.

41. The speaker's aim is to (IELTS 1 - test 1 )

A. Introduce students to university expectations.

B. Introduce students to the members of staff.

C. Warn students about the difficulties of studying.

D. Guide students round the university.

Significantly, items of this latter kind - requiring test takers to take account of the different paragraphs of a listening excerpt - were the only tasks found in the corpus that called for engagement at this whole text level.

From the examples above we can see that multiple choice items in the IELTS listening test probe a variety of textual units, ranging from the very local to the very global, as shown in Figure 2. However, generally speaking, it needs to be noted that, in multiple choice items, the degree of locality of engagement with the listening material is far more than the degree of global engagement with the material and it is observed that many items in the corpus, about more than half of the items, required the local engagement with the listening material between one to three sentence levels.

\section{Type of engagement}

As was the case with the level of engagement, IELTS multiple choice tasks in our corpus resisted any simple generalization regarding the way test takers needed to engage with the material. The sample items above suggest a variety of modes. Thus, items 1 and 2 of sample 2 (presented in Appendix 1), requiring identification of quite specific information (i.e. Andrew's number of work years and the speaker's warning about using the computer and internet), is clearly of a literal type. For example, to answer item1, test takers need to locate the synonymous or identical specific information required by the item in the conversation. Therefore option $\mathrm{D}$, three years is found to be the answer re- 
garding the sentence, working in the administration section of the local hospital for last three years, in the following extract of the conversation:

ANDREW: Yes I've been working in the administration section of the local hospital for last three years.

In contrast to items 1 and 2 , items of 3 and 4 of the sample require interpretive understanding of the material. For example, item 3 involves the interpretive engagement with the two sentences of the whole text.

24. To support the production, research material was used which described (IELTS 10, test 3)

A. Political developments.

B. Changing social attitudes.

E. Economic transformations.

It's noted that, test takers cannot respond to this question by literal understanding of the material, they need to use their background and pragmatic knowledge to select the correct option.

ROB: Well. She found these articles from the 1950s about relationships between children and their parents, or between the public and people like bank managers or the police were shifting.

\section{Correct answer: B}

Finally, item 4 of the sample, which asks test-takers to consider how the contents of the whole listening text can be encapsulated in a single phrase or sentence for the purpose of establishing the purpose of the lecture (i.e. 'introduce students to university expectations'), involves a more 'interpretative' engagement.

41. The speaker's aim is to (IELTS 1 - test 1 )

A. Introduce students to university expectations.

B. Introduce students to the members of staff.

C. Warn students about the difficulties of studying.

D. Guide students round the university.

To answer these kinds of items test takers need to take account of the whole listening conversation or lecture, in this example the whole seven paragraphs of the lecture. Indeed these item types entail the broadest level and type of engagement.

Overall, the engagement with listening material in $\mathrm{mul}$ tiple choice tasks was concluded to be the all four configuration of the framework. As can be perceived from sample items above, four configurations were determined relating to the level and type of engagement with listening material: local - literal, global - literal, local - interpretive and global - interpretive, whilst with some variation noted around them. An attempt has been made to capture this variation in Figure 2 below. Considering this task format, as was noted, the degree of locality and literalness of engagement with the listening material were identified to be more than the degree of other dimensions of engagement with the material. The preceding analysis gives the configuration shown in Figure 2.

\section{Type 3: Multiple option items}

About 10.3 percent of all item types in the corpus were found to be multiple option format with almost all relying on a different - option structure ranging from five to seven options depending on the rubric of the items. Three types of this format were observed throughout the corpus based on the rubric of the items and the options offered: two expected - response multiple options, three- expected - response multiple options and four-expected response multiple options. As a matter of fact, it was observed that by increase in the selection of expected answers, the number of options of an item was also increased. For example, items with five options required candidates to select two correct answers, items with six options expected the three true responses from test takers and items that offer seven options demanded test takers to choose four correct answers. Therefore, the number of options in this format depended on the rubric of the items. Amongst the three kinds of this format, two expected - response multiple options was identified to occur more frequent than the two other kinds in the corpus accounting for 6.5 percent of all types by occurring 25 times in the corpus. Three expected - response and four-expected response multiple options were also observed to be accounted for 2.8 percent of all task types, in a way that the first type had occurred ten times and the second type one time in the corpus.

Item 1 and item 2 included in the sample 3 (shown in Appendix 1) are examples of the multiple option task format, showing two sample items representing two kinds of text level and type of engagement. It is noted that, four-expected response multiple option format was not analyzed on an individual basis because of its minimal presence in the corpus $(<0.2 \%)$, occurring one time throughout the corpus and its resemblance to the other two kinds of this format in terms of level and types of engagement with listening material.

\section{Level of engagement}

As the rubric of this task type requires searching for the several items (options) in the listening material, the level of engagement in this format is clearly at a supra-sentential level. To respond to sample items of sample, for example, test takers need to take account of the whole speech and all five options of the item in order to distinguish and select options which are required by the items. Therefore, this task type can't be responded, for example, by a section of a paragraph, because, in order to confirm the truth-value of other options regarding the requirement of an item, one needs to acknowledge the whole speech and, hence completion of such items necessitates engagement with several separate sections of the listening material. In almost all cases in the corpus, the unit of speech to be negotiated in the multiple option tasks was the paragraph. Some variation was noted regarding the length of these paragraphs. In sample item 2, for example, the relevant paragraph is 17 sentences long (217 words); in sample item 1 it is considerably shorter, running to 7 sentences ( 84 words). In the whole corpus, the average paragraph length was 9 sentences. It is noted that, as stated above, only one four - expected response multiple option format has been observed in the corpus requiring one paragraph running to 12 sentences to answer the item. Generally, for multiple option task format, it's concluded that 
the rubric of an item and its options would not identified to have an effect on the level of speech required to answer the item. That's why in some of two - expected response and three - expected response multiple option items, the required level of speech was observed to be similar to that of four expected response item. Overall for this task type, we can say that the level of engagement is on 'global' scale on the local - global continuum (see Figure 2).

\section{Type of engagement}

To complete Multiple option tasks, test-takers need to be able to first match up the options provided by an item with the propositional content of them in listening material and then decide about the correctness of the options according to the rhetorical category upon which the item is constructed. Many items of this task type have been found to draw on various rhetorical categories (e.g. change and improvement, advice and suggestion, advantage and disadvantage and etc.). Thus, in sample item 1 (sample 2, Appendix 1), we can see that the relevant rhetorical category for the section of speech in question was 'advice and suggestion' (getting advice from the Union), and in item 3 of the sample, this category was 'agreement and disagreement' (Sandra's agreement regarding to the inclusion of topics in her proposal).

The task for test-takers then, in many instances, is to be able to identify the relationship between the content of the designated section of listening material, and this broader rhetorical unit around which the prompt and its options are structured. In the case of item 1 of sample 3, this requires drawing a semantic link between the category of 'advice and suggestion' in the prompt, and various 'advising' elements in the text - for example, i) certain key lexis (e.g., advice, offering, help, service) and ii) key structures (e.g., officer who can give advice on legal problems). Similarly, in item 2 of the sample, the task for test takers is to be able to identify how key agreement constructions such as I thought, I'd agree, it's not immediately relevant to your proposal, I'd like to see something about the local wildlife and vegetation - correspond to the rhetorical category of 'agreement and disagreement'. I note in passing that, the wide ranges of rhetorical functions were identified to be used in the construction of the multiple option prompts. The more prominent of these identified in the corpus are shown in Table 2, along with the prompt samples for each category.

Beside the specific rhetorical categories included in the table above, it was observed also some other prompts which were notable in the first instance for their lack of reference to the particular rhetorical units evident in many of the other prompt samples (e.g. agreement, cause, etc.):

- Which three things can students have with them in the museum?

- Which two activities can students do after the tour at present?

- Which two types of course work are required each month on the part time course?

It was found that, multiple option tasks require locating quite specific identical or paraphrase and synonymous information of options in the listening material that is a kind of lit- eral engagement with the material. For example, to respond to item 2 of sample 3 (presented in Appendix 1), candidates need to search for the identical or synonymous equivalent of options in the conversation and select the three of them that are correct regarding the rhetorical category upon which the item is constructed. In other words, the task for test takers is to first look for key structures, words and phrases related to the rhetorical category of the prompt in the conversation, then match up the information of the options and conversation with one another, and finally select the three choices agreed by Sandra:

Choose THREE letters, A - G.

Which THREE topics does Sandra agree to include in the proposal?
A. Climate change
B. Field trip activities
C. Geographical features
D. Impact of tourism
E. Myths and legends
F. Plant and animal life
G. Social history
Correct responses:
B. Field trip activities
C. Geographical features
F. Plant and animal life

C. Geographical features $\rightarrow$ One thing I needed to focus on was the sandstone plateaux and cliffs themselves. The way they tower up from the flat landscape is just amazing.

B. Field trip activities $\rightarrow$ I think an indication of what the students on the trip could actually do when they get there should be far more central

F. Plant and animal life $\rightarrow$ And I'd like to see something about the local wildlife, and vegetation too

Generally, two types of multiple option format were observed in the corpus in terms of level and type of engagement with listening material. 1 . Tasks that require mid global - literal

Table 2. Rhetorical categories used in multiple option prompts

\begin{tabular}{ll}
\hline $\begin{array}{l}\text { Rhetorical } \\
\text { category }\end{array}$ & Sample prompt \\
\hline Cause/reason & $\begin{array}{l}\text { Which two reasons does Jeanie give for } \\
\text { deciding to live some college clubs? }\end{array}$ \\
$\begin{array}{l}\text { Advantage/ } \\
\text { benefit }\end{array}$ & $\begin{array}{l}\text { What two advantages does the speaker say } \\
\text { Rexford University has for the students he is } \\
\text { speaking? }\end{array}$ \\
$\begin{array}{l}\text { Change and } \\
\text { improvement }\end{array}$ & $\begin{array}{l}\text { Which two facilities at leisure club have } \\
\text { recently been improved? }\end{array}$ \\
$\begin{array}{l}\text { Advice and } \\
\text { suggestion }\end{array}$ & $\begin{array}{l}\text { Which two of the following are offered free } \\
\text { of change at Shore Health Center? }\end{array}$ \\
$\begin{array}{l}\text { Interest and } \\
\text { favorite }\end{array}$ & What type of films does Louis like? \\
$\begin{array}{l}\text { Agreement and } \\
\text { disagreement }\end{array}$ & $\begin{array}{l}\text { Which three topics does Sandra agree to } \\
\text { include in the proposal? }\end{array}$ \\
$\begin{array}{l}\text { Saying and } \\
\text { expression }\end{array}$ & What does Charles say about his friends? \\
\hline
\end{tabular}


engagement. 2. Tasks that involve global - literal engagement with material. Overall, the general picture of level and type of engagement for multiple option task format is varied along the continuum from the mid - global to global engagement on local - global axis along with the stable literal engagement and no variation on literal - interpretive axis. In the grid shown in Figure 2 , an attempt has been made to account for this task variety.

\section{Type 4: Information category match}

Information-category match tasks were the fourth task type based on the total occurring times in the corpus accounting for $7.1 \%$ of all task types (Table 1 ). Under this format, test-takers were supposed to match information from the listening material with a particular information category to be selected from a range of category options and hence with items. As Moore, Morton \& Price (2012) in their reading study stated that the category type utilized in the manipulation of these tasks is conspicuous in some manner in the reading passage, and which could be used as a foundation for distinguishing main information included within the text, it can be assumed that, the task for listeners is correspondingly similar to the readers in a way that they need to match up the related information contained within the listening material that is provided by the prompt as a range of category options with the individual items. Thus, in almost all tasks, the task for test takers is listening to the material, searching for individual items and finding them in the material and matches the options with the items based on the related section of the listening material.

Although it has been observed that responding to this task format requires searching orderly for the items and options from following the first section of the text to the last section (e.g. first item requires scrutiny of the initial sentences of the text and the last item necessitates detection of the last sentences of the text) in a moving from items to options manner, overall, it can be premised that there is a simultaneous listening endeavor underlying this task type for listeners. For the purpose of comprehensive scrutiny of information-category match task format, some of the category-types noted in the corpus of this task type are exemplified in the following Table 3 along with their related prompts:

Thus, in Sample 4.1 (presented in Appendix 1) below, a task based on a listening comparing the types of different Dolphins, the category of dolphin type is used as the distinguishing element. In sample 4.2 also a category of location functions underlying the task.

\section{Level of engagement}

Information-category match items were generally found to be concerned with the locating of fairly specific information in the listening material (e.g. dolphin type in sample 4.1, shown in Appendix 1). Considering sample 4.1 for example, candidates need to make one to one correspondences between the items and the options based on the information they get from the speaker. Thus, they need to identify that the following statement concerning the type of dolphin pertains to which one of the dolphins:
1. (Which dolphin) It has not been seen this year.

Completion of such an item thus necessitates engagement with just limited section of the listening material, in this case half of a sentence, as follows:

Echo is being rather elusive this year and hasn't yet been sighted by our observers.

\section{Correct Response $=\mathbf{E c h o}($ Option B $)$}

Therefore, as candidates are listening to the material, they should simultaneously focus on both items and options and match up them according to the information they grasp. It is noted that, the items of this task type occurs in a sequence fashion in the listening material from the initial to the last section of the lecture or conversation and test takers need to follow the items in an order from the first sections of the listening material to the last section of it and should not confuse the items and options with each other. It means that, for example, the first item is dealt with the initial section and the last item is concerned with the last section of listening material.

However, some variation was observed in the corpus regarding the length of speech required to match up the items with options. This length was generally found to be varied from half of a sentence to 7 sentence paragraph. In Sample 4.2 (shown in Appendix 1), for example, the required length of speech necessary to respond the item, is a paragraph including7 sentences (98 words):

2. (Which section of the university deal with) Training in specialized computer programs

LECTURER: Some of you may be interested to know that the library is offering specialized training sessions on writing a dissertation. Obviously this is not relevant to those of you who are undergraduates; it is just for postgraduates. Your department will discuss the planning stage of the dissertation - i.e. what you are going to do - with you and we will focus on the structure of it. However the training will also include some time on the computers. I realize most of you know how to organize files but we can show you the different ways to run data programs.

\section{Correct Response $=$ Library staff $($ Option B)}

This particular characteristic of Information-category match tasks means that whilst engagement is generally at a local level, it is not as narrowly local as we have seen for

Table 3. Category types used in information - category match prompts

\begin{tabular}{|c|c|}
\hline Category - type & Prompt \\
\hline Location & $\begin{array}{l}\text { Where can each of the following items be } \\
\text { found? }\end{array}$ \\
\hline Job/action & $\begin{array}{l}\text { What action is needed for the following } \\
\text { stages in doing the 'year abroad' option? }\end{array}$ \\
\hline $\begin{array}{l}\text { Style/ } \\
\text { characteristics }\end{array}$ & $\begin{array}{l}\text { Which painting style have the following } \\
\text { features? }\end{array}$ \\
\hline Time & $\begin{array}{l}\text { In what time period can data from the } \\
\text { float projects help with the following } \\
\text { things? }\end{array}$ \\
\hline Opinion & $\begin{array}{l}\text { Which opinion does each person express } \\
\text { about Box Telecom? }\end{array}$ \\
\hline
\end{tabular}


other 'specific information' task types (e.g. Completion task types) and the locality of engagement underling this task type has been found to be varied from more local to mid-global level of engagement (see Figure 2).

\section{Type of engagement}

The dolphin example (sample 4.1, Appendix 1) suggests a highly literal engagement with listening material. In this case, the task for test takers is to identify specific information concerning the specific feature concerned with each dolphin:

\section{Comment:}

It has not been seen this year.

Relevant section in listening material:

Echo is being rather elusive this year and hasn't yet been sighted by our observers.

\section{Correct Response $=$ Echo $($ Option B $)$}

Almost the same as dolphin example, university example (sample 4.2 Appendix 1) requires literal engagement with material. In this case, test takers are expected to match up each of the items provided by the prompt with their related options based on the category of 'sections of the university' as they listen to the lecture. The only difference between the exemplified item of this sample and previous one is that, the item of sample 4.2 obligates literal understanding of the material in a scattered fashion or in different level of engagement in comparison with the item of sample 4.1. Overall, the type of engagement with material in Information-category match tasks was concluded to be quite literal. An attempt has been made to capture this variation in Figure 2 below.

\section{Type 5: Labeling}

After information-category match task type, the next most common format by number of occurring times accounting for $4.8 \%$ of all task types in the corpus (Table 1) was the $L a$ beling task type. Four kinds of this task format was observed in the corpus: labeling the map; labeling the diagram; labeling the plan; labeling the chart. In these tasks, depending upon the rubric of the prompt, test-takers are presented with a map, plan, chart or a diagram, from which key information/ lexis/numbers has been removed. The task for test-takers is to draw on the listening material to restore the omitted information and label the provided graphical stimulus by the prompt. I noted two alternative formats used for this task type: 1) Tasks where there was a number of word options to choose from; and 2) tasks where no options were provided. In the 'no options' format, test-takers are instructed to limit their responses to a maximum of two or three words and/or a number from the listening material. Examples of the two formats are shown in Samples 5.1 and 5.2 presented in Appendix 1.

\section{Level of engagement}

As far as speech level is concerned, it has been found that, like other specific information items, many of labeling items in the corpus required locating for specific area of listening material from candidates. In this respect, candidates were needed to engage with limited extent of the conversation or lecture related to the relevant places of the graphical shape (e.g. pan, map, etc.) provided by the prompt in order to answer the task. For example to respond to the item of sample 5.1 (shown in Appendix 1):

Cut into center and 33..............the cut.

Test takers were expected to locate the appropriate word fitting in the blank by taking account of the limited section of the speech entitled; Introduction to Hat-Making:

\section{Relevant section of listening material:}

We each made, first of all, a conical hat by.... er... if I show you now... cutting out a circle and then making one cut up to the center and then.... er.... overlapping the cut like this this. a conical hat that sits on your head.

Correct response: Overlap

Overall, it was found that most tasks of this type required engagement at or around sentence level. Accordingly in the analysis, such tasks were assigned to the more local end of the local-global continuum.

In performing such an analysis, one also needs to consider some of map labeling tasks that suggest engagement at a different speech level. To respond such tasks, individual items could not be treated entirely in isolation, but instead they needed to be considered in relation to the whole graphical positions of the map, as well as to the relevant section of the listening material. Thus, for example, in completing items 6, 7 and 8 from Sample 5.2 shown in Appendix 1, one is not able to confirm the answer to 8 without looking at the map and establishing the likely response to 6 and 7 and, hence appraising broader units of the speech. Thus, establishing this kind of sequential item responding, in which, answering later items depend upon responding former items, points to the span of information in the listening material that requires some appraisal of the listening content more than the items of other labeling items, and so for this kind of tasks, the engagement is judged to be at a mid - global level.

\section{Type of engagement}

Whilst the level of engagement in some labeling tasks extends beyond the single proposition, the way in which test takers need to engage with material is arguably a fairly literal one in responding all kinds of this task type. In this case, to respond to some of these tasks, test takers are supposed to locate either the non-variant or variant version of information of the prompt in the listening material in order to fill in the blanks of the sentences related to the graphical stimulus of the prompt as can be seen in the example from sample 5.1.

These non - variant and variant relationships between two speech units of similar or different length were also found to be functioning between the options provided by the prompt and the equivalent information of listening material in labeling tasks that required candidates to label the graphical stimulus of the prompt with the provided options.

In some other cases that obligated literal level of engagement with material, in the absence of propositional content contained in the prompt, there was a need for finding the indispensable information related to various graphical positions 


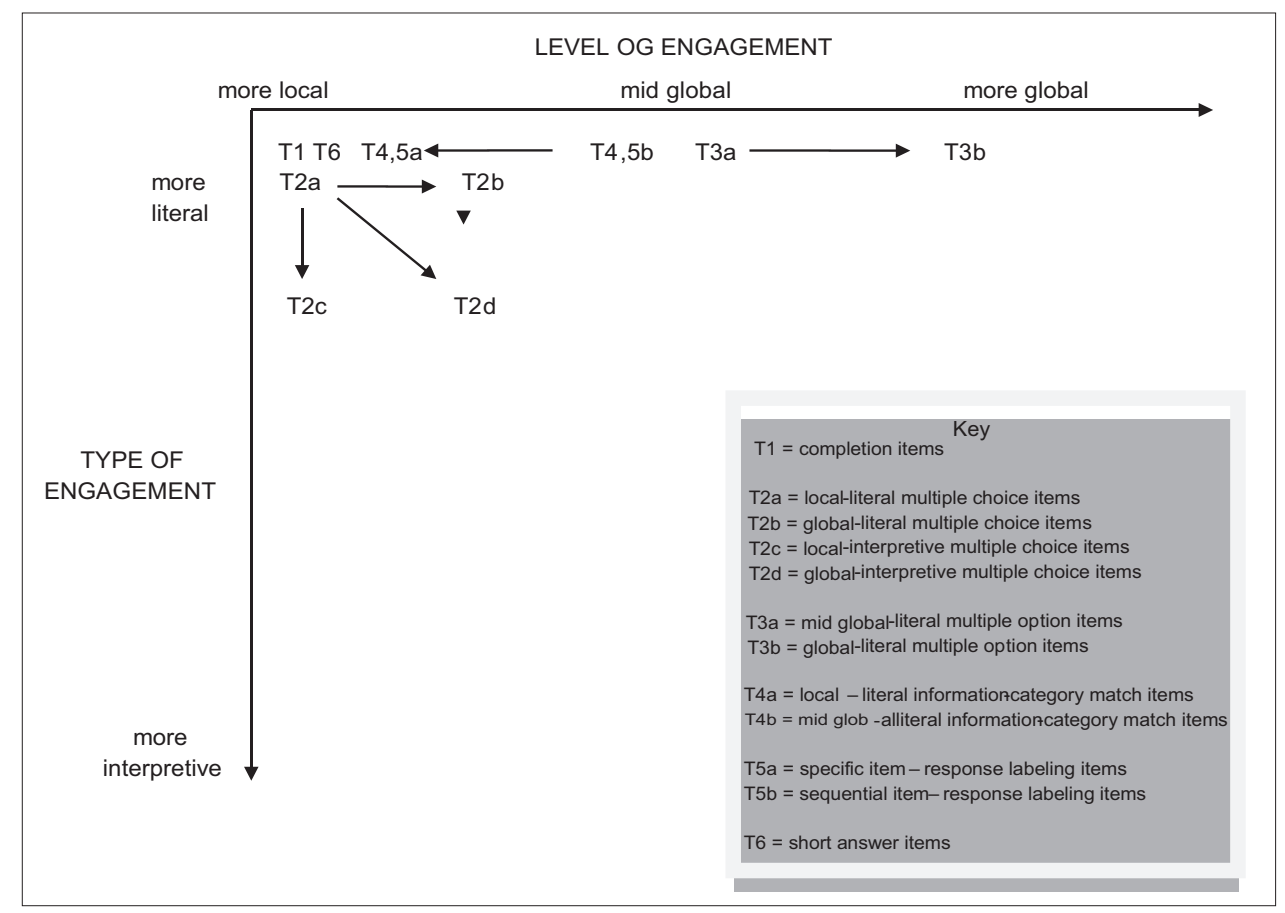

Figure 2. Analysis of IELTS listening task types

of a diagram, map, plan or chart in the listening material and then, creating a correspondence between this information and that of listening material for the purpose of finding the missing parts. In addition to these relationships, some lexical entities (e.g. left/right; up/down; above/below; center; near, next to/ far away; at the end of; and etc.) related to various directional sides in graphical stimuli are found to be frequently repeated in the listening material related to each graphical figure. In this respect, test takers could utilize the frequency of these lexical items to label the graphical stimulus decisively. Some of these lexical words and phrases are extracted from the listening transcription of sample 5.2 (shown in Appendix 1) and are illustrated bellow along with their related sentences:

- The end of; you walk on to the end of this corridor in front of you.

- $\quad$ Along past, past; walk along past the Language Laboratory and then past the Library.

- Next to, the same side; next to the Language Lab, on the same side, and facing you is the Main Hall.

- Go down; you go down to the end of this corridor again

- turn left, turn right, away; don't turn left; turn right, away from the Main Hall.

- Near, apposite; the staff room is near the main entrance, on the left over there, just opposite the Reception desk.

Overall, whatever the relationships and lexical entities were, it was found that the specific information-detection characteristic of labeling tasks convince us to assign such tasks to the more literal end of the literal-interpretive continuum (Figure 2).

\section{Type 6: Short answer}

Short answer tasks were one of the less frequently occurring tasks accounting for $3.4 \%$ of all task types in the corpus (Table 1). Under this format, test-takers were expected to pinpoint quite specific information from the listening material in response to mostly basic wh-questions. A requirement of answers in this task type was that responses needed to be restricted to no more than two, three or four words (or numbers), and that responses were composed only of lexis drawn from the listening material. An example of this format is presented in Sample 6 shown in appendix 1.

\section{Level of engagement}

In regard to speech level, short answer items, similar to other specific information items analyzed in previous sections, anticipate local level of engagement with the listening material from listeners as shown in the item below.

1. When will Louise's card be ready?

\section{Relevant section of listening material:}

MR MAX: Yes, that's it. You can borrow videos now, if you like, but your card won't be ready until next week.

Correct response: Next week

Based on the items cited above, there is no doubt that these tasks based on their expectation from candidates that is, to trace specific information in minimal units of speech, were allotted to the higher local end of local - global continuum.

\section{Type of engagement}

As can be realized from items presented above, it must be admitted that the requirement of short answer task type in IELTS listening module is to focus on quite specific items of information (e.g. the time that Louise's card will be ready). Having looked at this issue, it would be said then that this feature necessitates a very basic form of speech comprehension, and so this task format is situated very much towards the literal end of our 'literal- interpretative' continuum. To 
sum up, the forgoing analysis indicates that the short answer format constitutes the most 'literal' and most 'local' position on the matrix below (Figure 2).

\section{DISCUSSION}

According to the findings of the analysis of listening tasktypes, three groups of tasks were identified in the corpus:

1. Tasks fitting with one configuration from all four configuration of the analytical matrix.

2. Tasks fitting with two configurations from all four configuration of the analytical matrix.

3. Tasks fitting with all configuration of analytical matrix.

\section{Tasks Fitting with One Configuration of the Analytical Matrix}

Two kinds of task-types in the IELTS corpus were discovered and recognized to fit with distinctly one-configuration pattern. These groups of tasks were those requiring primarily a basic understanding of relatively small textual units (words, phrases, sentences, inter-sentences). These one-configuration requiring task-formats (more than half of all tasks in the corpus) included; completion task types; and Short answer task format (2 of 6 task-types).

\section{Tasks Fitting with Two Configurations of the Analytical Matrix}

Based on the analysis of task-types in the IELTS corpus, three tasks were found to fit with two configuration of taxonomic framework: Multiple option, Information- category match tasks, and labeling task format. The first of these task types, the 'multiple option task', was the more common in the corpus, with instances identified in a range of IELTS tests. The required configuration for this task was identified to be 'mid global - literal' and 'global - literal' patterns. In this regard, in these tasks, the requirement for test takers was to engage in a literal manner with less global texts and, in some other tasks they needed to literally understand the larger units of texts. However, items of this second type arguably constituted a special case.

Less prominent than the multiple option task fitting a 'two-configuration' pattern, were information - category match and labeling tasks. These task types were found to be more 'local-literal' in their orientation (i.e. like completion and short answer task types), but were thought also to slightly inhabit the 'global-literal' region of the analytical matrix in a very few cases. In majority of these tasks, test takers were expected to primarily engage with basic understanding of the smaller units of material. In the other few cases, the prerequisite for them was literal comprehension of the larger textual units.

\section{Tasks Fitting with All Configurations of Analytical Matrix}

The only task-type in our corpus that clearly traversed the four configuration of the analytical matrix was multiple choice task format. Items of this task-type were found to be 'local - literal', 'global - literal', 'local - interpretive', and 'global - interpretive' in their orientation. It is important to note that, unlike the other items, the only items in our corpus that clearly related to the 'global-interpretive' domain were certain multiple choice items that required an appraisal of the listening text as a whole in a pragmatic manner (e.g. items that require understanding the lecturer's aim in the lecture). However, items of this type arguably constituted a very few cases.

\section{CONCLUSION AND IMPLICATIONS}

Overall, the analysis found that a majority of tasks in the IELTS corpus were of a definitely 'local literal' orientation, requiring mainly a basic comprehension of relatively small textual units. Even, some of those tasks requiring the configuration beside the 'local - literal' one, (i.e., Labeling, Multiple option, and information - category match, and multiple choice), were assumed nevertheless to predominantly occupy the 'local-literal' region of our taxonomic framework. It needs to be accepted that findings are based on a broad sample of items, despite the fact that they are not derived from actual live test materials. Supposing however, that the samples used demonstrate some association of contemporary item-design practices at IELTS, we would contend, that the analysis reveals a comprehensive representation of the tests' general construct- that is, a conspicuous direction towards 'local' and 'literal' nature of listening.

The findings of the present study suggest some practical implications not only for the IELTS participants and teachers but also for IELTS material preparation experts and course designers. The local-literal engagement underlying most of IELTS listening tasks can have a considerable effect in students' selection and implementation of the appropriate techniques and methods required for preparing themselves for the listening section of the IELTS test and for performing appropriately in the test. According to the analysis of tasktypes, almost all tasks in the IELTS corpus were identified to require relatively literal comprehension of the smaller textual units. Therefore, participants of the IELTS should be made aware of this requirement, and now that there is no need for them to bring a broadly pragmatic approach to the listening for the majority of task-types, instead they should equip themselves with bottom - up oriented skills of listening in responding most of the IELTS listening items. On the other hand, If teachers, course designers and material preparation experts know what kind of processes and procedures are required and yield the best results in the IELTS listening tests, they will be able to facilitate the students learning by exposing them to the appropriate kinds of strategies, methods and materials required to more successfully respond the test.

\section{REFERENCES}

Alderson, JC. (2000). Assessing reading, Cambridge: Cambridge University Press.

Badger, R. \& Yan, X. (2012). The use of tactics and strategies by Chinese students in the listening component of IELTS. In L. Taylor \& C. Weir (Eds.), Studies in language testing, IELTS collected papers 2 (pp.454-486), Cambridge, UK: Cambridge University Press.34.

Breeze, R. \& Miller, P. (2012). Predictive validity of the IELTS listening test as an indicator of student coping 
ability in English-medium undergraduate courses in Spain. In L. Taylor \& C. Weir (Eds.), Studies in language testing, IELTS collected papers 2, (pp. 487-518). Cambridge, UK: Cambridge University Press 34.

Carroll, J. B. (1987a). 'New perspectives in the analysis of abilities' in R. R. Ronning, J. A. Glover, J. C. Conoley, and J. C. Witt (eds.): The Influence of Cognitive Psychology on Testing. (pp.267-84). Hillsdale, NJ: Lawrence Erlbaum Associates.

Cronbach, L. J. and P. E. Meehl. (1955). 'Construct validity in psychological tests.' Psychological Bulletin 52(4), 281-302.

Field, J. (2012). The cognitive validity of the lecture-based question in the IELTS listening paper. In L. Taylor \& C. Weir (Eds.), Studies in language testing, IELTS collected papers 2,(pp.391-453). Cambridge, UK: Cambridge University Press. 34.

Fulture, G. (2010). Practical language testing, London: Hodder education.

Fulcher, G. and Davidson, F. (2007). Language Testing and Assessment: An Advanced Resource Book. London and New York: Routledge.

Fulcher, G. and Davidson, F. (2009). Test architecture, test retrofit. Language Testing, 26(1) 123-144.

IELTS. (2007). The IELTS handbook, UCLES/British Coun- cil, IDP Education Australia: Cambridge.

Kerlinger, F. and Lee, H. B. (2000). Foundations of Behavioral Research. Fort Worth, TX: Harcourt College Publishers.

Moore, T. Morton, J. Price, S. (2012). Construct validity in the IELTS Academic Reading test: A comparison of reading requirements in IELTS test items and in university study. IELTS Research Reports, (Vol.11). Swinburne University. IELTS Australia and British Council.

Moore, T. and Morton, J. (2007).Authenticity in the IELTS Academic Module Writing Test: A comparative study of Task 2 items and university assignments. In L. Taylor and P. Falvey (Eds.), IELTS collected papers: Research in speaking and writing assessment (pp. 197-248). Cambridge: Cambridge University Press.

Nakatshuhara, F. (2012). The relationship between test takers' listening proficiency and their performance on the IELTS Speaking test. In L. Taylor \& C. Weir (Eds.), Studies in language testing, IELTS collected papers 2. (pp. 519573). Cambridge, UK: Cambridge University Press. 34.

Weir, C. (2005). Language Testing and Validation. London: Palgrave Macmillan.

Weir, C.J. and Urquhart, AH. (1998). Reading in a second language: Process, product and practice, New York: Longman.

\section{APPENDIX}

\section{APPENDIX 1}

IELTS task samples used in the analysis:

\section{Note completion items.}

1. Complete the notes bellow. Write one word for each answer. (IELTS 10, Test 1)

\section{SELF - DERIVE TOURS IN THE USA}

\section{Example}

Name:

Address:

Postcode:

Phone:

Heard about company from:

Possible self-drive tours

Trip One:

Los Angles: customer wants to visit some 3

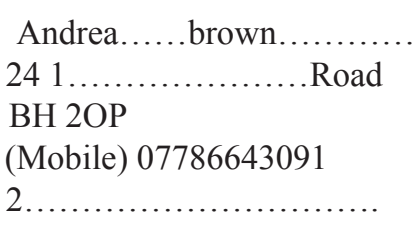

parks with her friends.

2. Complete the notes bellow. Write no more than two words for each answer. (monologue) (IELTS 9, Test 1)

\section{Mass Strandings of Whales and Dolphins}

Parasite

e.g. some parasites can effect marine animals' 4 ,which they depend on navigation

Toxins

Poisons from $5 \ldots \ldots \ldots \ldots \ldots \ldots$..................... commonly consumed by whales. e.g. cape Cod (1988) - whales were killed by sax toxin. 


\section{Sample 1: Note Completion items}

1. Andrew has worked at the hospital for (IELTS 5 - test 1), (local - literal)
A. Two years
B. Three years
C. Five years

2. The speaker warns the students that: (IELTS 5 - test 4$)$, (global - literal)

A. Internet material can be unreliable.

B. Downloaded information must be acknowledged.

C. Computer access may be limited at times.

3. To support the production, research material was used which described (IELTS 10, test 3), (local - interpretive)
A. Political developments.
B. Changing social attitudes.
E. Cconomic transformations.

4. The speaker's aim is to (IELTS 1 - test 1$)$, (global - interpretive)
A. Introduce students to university expectations.
B. Introduce students to the members of staff.
C. Warn students about the difficulties of studying.
D. Guide students round the university.

\section{Sample 2: Multiple choice sample}

Circle TWO letters A-E. (IELTS 2, Test 3)

Which TWO of the following can you get advice about from the Union?
A. Immigration
B. Grants
C. Medical problems
D. Personal problems
E. Legal matters

Choose THREE letters, A - G. (IELTS 8, Test 1)

Which THREE topics does Sandra agree to include in the proposal?
A. Climate change
B. Field trip activities
C. Geographical features
D. Impact of tourism
E. Myths and legends
F. Plant and animal life
G. Social history

\section{Sample 3. Multiple option items}

Information - Category match 1

Which dolphin does Alice make each of the following comments about? (IELTS 10, test 3)

Write the correct letter. A, B, C or D, next to questions $16-20$.

\section{Comments}

16. It has not been seen this year.

17. It is photographed more than the others.

18. It is always very energetic.

19. It is the newest one in the scheme.

20 . It has an unusual shape.

\begin{tabular}{l}
\hline Dolphins \\
\hline A. Moon dancer \\
B. Echo \\
C. Kiwi \\
D. Samson
\end{tabular}


Sample 4.2: Information-category match - location as category

Labeling 1

Label the diagrams.

Write NO MORE THAN THREE WORDS for each answer (IELTS, 3 Test 2).

Introduction to Hat-Making

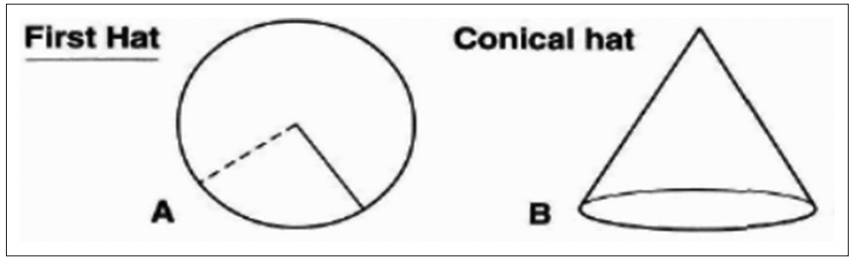

Cut into center and 33 the cut.

Sample 5.1: labeling sample, without options

\section{Labeling 2}

Label the rooms on the map below. (IELTS 3, Test)

Choose your answers from the box below and write them next to questions 6-10.

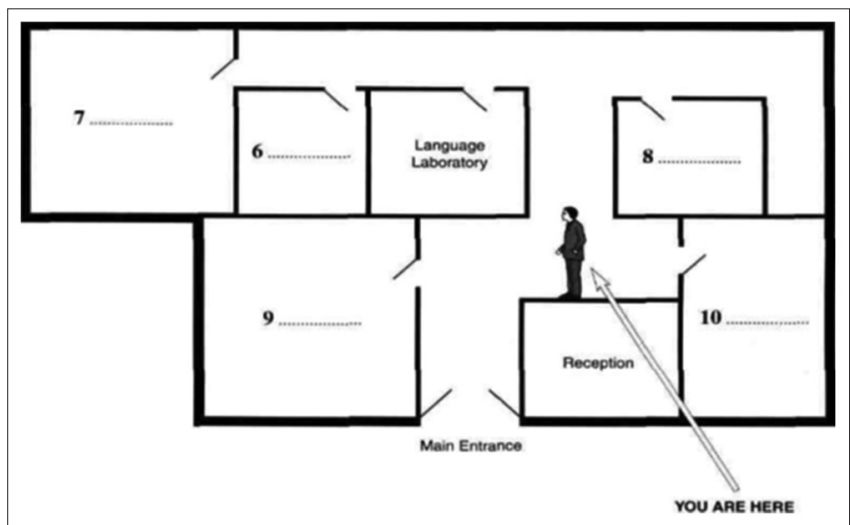

CL Computer Laboratory

DO Director's Office

L Library

MH Main Hall

S Storeroom

SAR Self Access Room

SCR Student Common Room

SR Staff Room

Sample 5.2: Labeling sample, with a number of options

Short answer items

Write NO MORE THAN THREE WORDS AND/OR A NUMBER for each answer.

1. When will Louise's card be ready?

2. How much does it cost to join the library?

\section{Sample 6: Short answer items}




\section{APPENDIX 2}

List of materials used in IELTS task corpus:

Cambridge IELTS 1: Examination papers from University of Cambridge ESOL examinations, Cambridge University of Press, Cambridge, 1996 (4 x Listening tests)

Cambridge IELTS 2: Examination papers from University of Cambridge ESOL examinations, Cambridge University of Press, Cambridge, 2000 (4 x listening tests)

Cambridge IELTS 3: Examination papers from University of Cambridge ESOL examinations, Cambridge University of Press, Cambridge, 2002 (4 x listening tests)

Cambridge IELTS 4: Examination papers from University of Cambridge ESOL examinations, Cambridge University of Press, Cambridge, 2005 (4 x Listening tests)

Cambridge IELTS 5: Examination papers from University of Cambridge ESOL examinations, Cambridge University of Press, Cambridge, 2006 (4 x Listening tests)

Cambridge IELTS 6: Examination papers from University of Cambridge ESOL examinations, Cambridge University of Press, Cambridge, 2007 (4 x Listening tests)

Cambridge IELTS 7: Examination papers from University of Cambridge ESOL examinations, Cambridge University of Press, Cambridge, 2009 (4 x Listening tests)

Cambridge IELTS 8: Examination papers from University of Cambridge ESOL examinations, Cambridge University of Press, Cambridge, 2011 (4 x Listening tests)

Cambridge IELTS 9: Examination papers from University of Cambridge ESOL examinations, Cambridge University of Press, Cambridge, 2013 (4 x Listening tests)

Cambridge IELTS 10: Examination papers from University of Cambridge ESOL examinations, Cambridge University of Press, Cambridge, 2015 (4 x Listening tests) 